\section{Apes cast out of Eden?}

\author{
W. C. McGrew
}

The Egalitarians - Human and Chimpanzee: An Anthropological View of Social Organization. By Margaret Power. Cambridge University Press: 1991. Pp. 290. £29.95, $\$ 44.50$.

OCCASIONALLY there comes a book that claims to change the whole picture in an area of science - that is, not just revise it but instead remake it. And when that book comes from one of the world's most important publishers of scholarship, it must be taken seriously.

Power says that most of what we think we know about the natural behaviour of our nearest living relation, the chimpanzee, is wrong. According to her, the two great field studies in Western Tanzania over the past 25 years are misleading and distorted. What has been reported by Jane Goodall and her colleagues at Gombe and by Toshisada Nishida and his colleagues in the Mahale Mountains must be junked. If Power is right, primatology is in a mess.

Her thesis is that chimpanzees studied in nature can be divided into two types: wild and provisioned. Wild apes are those "whose natural patterns of feeding and ranging have not ... been changed by artificial feeding". Examples emphasized are early studies by Adrian Kortlandt and Vernon and Frances Reynoldses, and the early research at Gombe and Mahale before provisioning began. (Provisioning is giving supplementary, artificial food such as bananas or sugar cane to accelerate habituation; habituation is the progressive tolerance by wild animals to being watched at close-range by humans.) Thus, provisioned apes "are not confined but fed almost all of their food by people". This, Power says, applies to all the ethological research at Gombe and Mahale since the mid-1960s.

Thus the effect of provisioning is devastating; "artificial feeding is a catalyst for a high degree of qualitative, negative social change among the provisioned groups, which spread in ripple fashion to distort all aspects of the adapted social order". Limited food led to violence. The corrupted chimpanzees became xenophobic, murderous, cannibalistic, incestuous, infanticidal, despotic, retarded, anxious, greedy and so on. In short, sociopathy became the norm.

The demise of wild chimpanzees is all the more regrettable because, according to Power, they are really egalitarian. They live in friendly, open societies that are nonaggressive, nonterritorial and nonhierarchical. The sexes relate through mutual dependence, and growing up is a matter of apprenticeship and acceptance. Child-rearing is collective, leadership is charismatic, sex is free, elders are wise, and the overall positive ambience is best exemplified in periodic 'carnivals', which are mass gatherings for socializing and reaffirmation.

The contrast could hardly be more stark, but it does not stand up. Field studies of chimpanzees cannot be so simplistically dichotomized; and neither Gombe nor Mahale actually fits Power's own definition of a provisioned population, because the artificial food provided only a fraction of the average daily intake of food. The heavy provisioning focused on by Power stopped long ago and was replaced by the giving of selective and intermittent snacks to individuals (not groups). Even this ceased years back, except in rare cases such as when medical intervention was called for. Power ignores this.

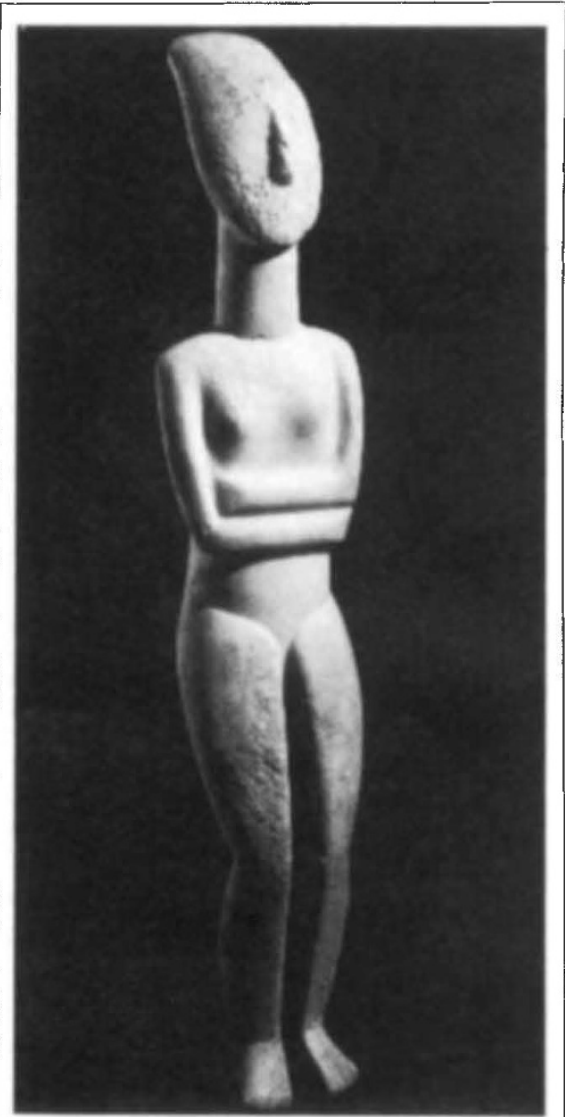

BETWEen 2700 and $2400 \mathrm{BC}$, craftsmen in the Cycladic Islands of Greece sculptured these marble nudes whose elegance and simplicity were not seen again until the work of Brancusi and Modigliani. The sculptures range in size from under 10 $\mathrm{cm}$ to life size; their most striking feature is their adherence to a canon - most are female, standing, have folded arms, and lack surface detail. A comprehensive and stunningly illustrated account of Cycladic art is given by Colin Renfrew in Cycladic Spirit, published by Thames and Hudson, $£ 32$.
What of research on unprovisioned, wild chimpanzees? The early studies cited by Power were admirable pioneering efforts done when expectations and standards were different, and all had their limits. They were short (usually lasting months instead of years) glimpses of usually unidentified subjects of unknown age and status. The apes could be observed only opportunistically, usually at a distance. However hard-won, the sparse data yielded only suggestive hypotheses rather than firm conclusions. Only at Gombe and Mahale did the researchers push on to more sustained and intimate studies of behaviour in the daily lives of well-known individuals.

But the truest test of Power's reinterpretation of chimpanzee life in nature is provided by the wild populations of apes that show competition, hierarchy, territoriality, sex differences and so on, but that, crucially, have never been provisioned. Power either fails to mention these cases or consigns them to the fine print of her notes section. The most striking omission is that of the chimpanzees of the Tai forest of Ivory Coast studied by Christophe and Hedwige Boesch. In a series of articles published in mainstream journals during the 1980 s, these authors described a chimpanzee society that, for example, competes forcefully for meat captured in frequent hunting forays.

So, why did Power get it wrong? She has sought to force chimpanzees into a Rousseau-like model borrowed from human foraging societies, depending heavily on Colin Turnbull and James Woodburn, while failing to acknowledge key differences. Unlike human gathererhunters, chimpanzees do not exchange their gains, and so are not mutually dependent in subsistence. Also, Power had tried to understand a complex species without ever having studied it or (apparently) without ever consulting anyone currently studying chimpanzees in the field. Finally, she has attempted to make sense of an intelligent, strategizing creature while largely ignoring the advances of modern evolutionary biology. Interpretations couched in terms of group or species selection have not proved fruitful for analysing vertebrate societies.

Provisioning is indeed a problematical field technique, as has been recognized for many years. It has rightly been largely abandoned. But it was unlikely to have been the Fall that cast out the apes from their equatorial Garden of Eden. Instead we must face up to the fact that chimpanzees are probably very like us, warts and all.

W. C. McGrew is in the Department of Psychology, University of Stirling, Stirling FK9 4LA, UK. 